\title{
Consecuencias de la Pandemia COVID-19 en la permanencia de la población estudiantil universitaria
}

Consequences of the COVID-19 Pandemic on the Permanence of the University Student Population

\section{Volumen 21, Número 3 \\ Setiembre - Diciembre \\ pp. 1-30}

\begin{abstract}
María Gabriela Regueyra Edelman Melissa Edith Valverde-Hernández Antonio Delgado Ballestero
\end{abstract}

Citar este documento según modelo APA

Regueyra Edelman, María Gabriela., Valverde-Hernández, Melissa Edith. y Delgado Ballestero, Antonio. (2021). Consecuencias de la Pandemia COVID-19 en la permanencia de la población estudiantil universitaria. Revista Actualidades Investigativas en Educación, 21(3), 1-30. Doi. 10.15517/aie.v21i3.46423 


\title{
Consecuencias de la Pandemia COVID-19 en la permanencia de la población estudiantil universitaria \\ Consequences of the COVID-19 Pandemic on the Permanence of the University Student Population
}

\author{
María Gabriela Regueyra Edelman ${ }^{1}$ \\ Melissa Edith Valverde-Hernández ${ }^{2}$ \\ Antonio Delgado Ballestero ${ }^{3}$
}

\begin{abstract}
Resumen: Con el propósito de aportar información sobre los efectos de la Pandemia en la permanencia de la población estudiantil de 10 carreras de la Universidad de Costa Rica, para la toma de decisiones de autoridades universitarias, se realizó un estudio cuantitativo exploratorio y descriptivo, en el marco del proyecto que investiga la permanencia del estudiantado en dicha institución. La información se recopiló por medio de un cuestionario en línea que estuvo a disposición de la población estudiantil entre diciembre de 2020 y enero de 2021. Se obtuvo respuesta de 974 estudiantes que participaron voluntariamente. Los resultados evidencian que en el I y II ciclo de 2020 se enfrentaron dificultades en las clases remotas: el 95\% enfrentó problemas de conectividad a internet, 95\% dificultades para adaptarse al proceso de enseñanza aprendizaje, el 75\% limitaciones de acceso a programas informáticos para realizar evaluaciones académicas, $89 \%$ dificultades de interacción en los trabajos grupales. Además, $98 \%$ indica niveles de estrés y $95 \%$ de ansiedad. Existe prolongación de la permanencia debido a que el $46 \%$ disminuyó la carga académica, $40 \%$ indica rezago en el avance en el plan de estudios a causa de que la carrera no ofreció algunos cursos y el $20 \%$ retiró o abandonó algún curso. El $4 \%$ de la población ya había decidido no matricular en el l ciclo 2021 y 12 \% aún no lo había decidido. Con estos datos se evidencia que la Pandemia COVID-19 provocó efectos en la permanencia de la población estudiantil en la universidad y que se requiere construir respuestas institucionales a las necesidades expresadas, a fin de garantizarle la permanencia $y$ graduación.
\end{abstract}

Palabras clave: educación superior, pandemia, permanencia, derecho a la educación.

Abstract: A quantitative exploratory and descriptive study was carried out to provide information on the effects of the Pandemic in the permanence of the student population of 10 majors in the University of Costa Rica, to aid the decision-making process of university authorities. The information was collected through an on-line questionnaire available to the students between December 2020 and January 2021. A total of 974 students volunteered to participate. The results evidenced that in the $1^{\text {st }}$ and $2^{\text {nd }}$ cycles of 2020 , there were difficulties regarding remote learning: $95 \%$ had internet connectivity problems, $95 \%$ had difficulties to adapt to the learning process, $75 \%$ had limitations to access software to carry out academic evaluations, $89 \%$ had difficulties to interact in group works. Furthermore, 98\% reported stress levels and 95\% anxiety. The permanence was prolonged because $46 \%$ decreased their academic burden, $40 \%$ reported falling behind in their course plan because the major did not offer some courses, and $20 \%$ withdrew or abandoned at least one class. Four percent of the population decided not to enroll on the $1^{\text {st }}$ cycle of 2021, and $12 \%$ had not yet decided. These data make evident that the COVID-19 pandemic affected the permanence of the student body of the university, and institutional efforts must be implemented to help students finish their studies and graduate.

Keywords: higher education, pandemic, permanence, right to education.

1 Investigadora de la Universidad de Costa Rica, en el Instituto de Investigación en Educación, San José, Costa Rica. Máster en Educación de la Universidad de Costa Rica. Dirección electrónica: gabriela.regueyra@ucr.ac.cr ORCID ID: https://orcid.org/0000-0001-5544-1311

2 Investigadora de la Universidad de Costa Rica, en el Instituto de Investigación en Educación, San José, Costa Rica. Egresada de Estadística de la Universidad de Costa Rica. Dirección electrónica: melissa.valverde h@ucr.ac.cr ORCID ID: https://orcid.org/0000-0003-0669-6320

3 Profesor de estadística de la Universidad Nacional, Heredia, Costa Rica. Máster en Sistemas de Información por el Instituto Tecnológico de Costa Rica. Dirección electrónica: antonio.delgado@ucr.ac.cr ORCID https://orcid.org/0000-0002-1256-3180

Artículo recibido: 26 de marzo, 2021

Enviado a corrección: 9 de junio, 2021

Aprobado: 16 de agosto, 2021

Los contenidos de este artículo están bajo una licencia Creative Commons 


\section{Introducción}

En el primer trimestre del año 2020 se inició una coyuntura que transformó la vida en todo el planeta, la pandemia del COVID-19, una situación de salud pública que continúa impactando más allá del área de la salud y que ha causado transformaciones en lo económico, lo social, lo ambiental y lo educativo, por citar algunos. Como indica Amador (2020), "La política pública y la regulación generada en torno a la pandemia no tienen precedentes" (p. 230). En el área de la Educación Superior, que es la que nos convoca, ha provocado una transformación profunda, que, en corto tiempo, pasó de un sistema educativo presencial a una educación remota con una población docente y estudiantil con poca o sin experiencia en este campo, además, sin saber cuándo se podrá regresar a la educación presencial, como señala Barrón (2020) "una coyuntura compleja dominada por la incertidumbre, permeada de noticias falsas, de la ambigüedad y de las contradicciones de la información emitida a diario" (p. 67)

En este contexto, la Universidad de Costa Rica (UCR), siguiendo con los lineamientos dictados por las autoridades sanitarias nacionales ante la Pandemia COVID-19, dispuso la continuidad del curso lectivo de 2020 por medio de clases remotas. Ante estas disposiciones, la población docente implementó los cursos planeados para lecciones presenciales a cursos con modalidad remota sin las condiciones adecuadas para esta nueva modalidad. Los efectos de esta coyuntura en la permanencia de la población estudiantil no se conocen en detalle.

Al concluir el año 2020 y de cara al año académico 2021, el equipo de investigación del proyecto Seguimiento a la permanencia de la población estudiantil ${ }^{4}$, tomó la decisión de indagar sobre las consecuencias de la pandemia del COVID-19 en la permanencia de la población estudiantil, de las carreras participantes en este proyecto, durante el I y II ciclos lectivos del 2020, y la intención de matrícula para el I ciclo 2021.

La finalidad del estudio fue aportar información oportuna para la toma de decisiones de las autoridades de las carreras ante un año lectivo distinto al anterior y muy distante de las experiencias previas. Se tomó como base, la investigación realizada por Aguilar y Pérez (2020) en la carrea de Ciencias de la Comunicación Colectiva de la Universidad de Costa Rica.

Los esfuerzos se centraron en identificar los recursos y limitaciones que tiene la población estudiantil relacionada con los dispositivos, conectividad a internet y acceso software para las labores académicas, las consecuencias de la pandemia en el avance

\footnotetext{
${ }^{4}$ Proyecto inscrito en el Instituto de investigación en Educación de la Universidad de Costa Rica, desde 2009. 
académico, desarrollo físico y mental de la población estudiantil, así como las consecuencias económicas y sociales en sus familias.

Con la información aportada por la población participante se identificaron necesidades y requerimientos específicos de la población estudiantil para continuar con los estudios. Esta información fue entregada a las autoridades de cada carrera antes de la matrícula del I ciclo 2021.

\section{Marco teórico}

En este apartado se exponen las bases teóricas que orientan la investigación y que se convierten en el lente para analizar y discutir los datos que surgen de la realidad observada. En línea con lo que indica Delgado (2014), "la realidad no existe sin el observador u observadora; es construida al ser observada, ya que quien observa la filtra con sus categorías cognitivas" (p.42).

\subsection{Educación superior como derecho}

Con la Conferencia Regional de Educación Superior de 1996, realizada en la Habana, y con la Primera Conferencia Mundial sobre la Educación Superior 1998, en París, se sientan las bases para concebir la educación como un derecho y un bien público. Sin embargo, afirma Del Valle (2008) que es en la Conferencia Regional de la Educación Superior 2008, celebrada en Cartagena de Indias, que se logra "la formulación más clara y contundente de la universidad como un derecho" (p. 50) y agrega "De esta manera, si para el 98 la fórmula fue de la élite al mérito, podemos decir que para el 2008 la fórmula que refleja sentido de la educación en la región es del mérito al derecho" (p. 51).

Desde la concepción de la educación como derecho se promueve la incorporación de la población estudiantil proveniente de sectores sociales tradicionalmente excluidos de este bien público y se concretan acciones democratizadoras y de justicia social, como son los programas de becas por condición socioeconómica, para grupos específicos de comunidades originarias y poblaciones con discapacidad, entre otros.

El derecho a la educación garantiza a toda persona el acceso al conocimiento socialmente acumulado, y transcender la visión de que la educación superior es únicamente para la formación técnica especializada para el mercado laboral, como lo señala Unzué (2008)", la universidad debe formar hombres/mujeres y ciudadanos, siendo el punto 
culminante del sistema educativo, y por eso se trata de un derecho, asociado a nuestra condición de ciudadanos" (p. 83)

Por lo tanto, la educación es uno de los derechos humanos fundamentales y la base para la exigencia y el ejercicio de los otros derechos, como se ratifica en la Declaración de Incheon titulada Hacia una educación inclusiva y equitativa de calidad y un aprendizaje a lo largo de la vida para todos, y emitida en el marco del Foro Mundial sobre la Educación celebrado en 2015, y "es esencial para la paz, la tolerancia, la realización humana y el desarrollo sostenible. Reconocemos que la educación es clave para lograr el pleno empleo y la erradicación de la pobreza" (Organización de las Naciones Unidas para la Educación, la Ciencia y la Cultura, Unesco, 2015, p.1)

Las declaraciones sobre la educación aportan directrices y acuerdos para caminar hacia una educación superior democrática, inclusiva y con equidad, orientaciones que se fortalecen con el cuarto objetivo de la Declaración de la Asamblea General de las Naciones Unidades: Transformar nuestro mundo: la Agenda 2030 para el Desarrollo Sostenible: "Garantizar una educción inclusiva y equitativa de calidad y promover oportunidades de aprendizaje permanente para todos" (Naciones Unidas, 2015, p.16).

Garantizar el derecho a la educación es realizar todos los esfuerzos necesarios a fin de que la población estudiantil ingrese, permanezca y se gradúe (Rovelli, 2008, p. 67). Sin embargo, esto está lejos de ser una realidad, ya que la ampliación en el ingreso de sectores tradicionalmente excluidos en América Latina no asegura la permanencia y la graduación, situación que es señalada por Ezcurra como una "inclusión excluyente" (2011, p. 26), ya que esta población tiene un bajo "capital cultural", a lo que refiere:

... no solamente, a algunas habilidades cognitivas y hábitos académicos críticos. Entre otros saber estudiar y saber aprender. Un saber que por una parte engloba un conjunto que Pierre Bourdieu (2005) denomina técnicas de trabajo intelectual y arte de organizar el aprendizaje y que abarca conocimientos como tomar apuntes en clase, preparar exámenes, estudiar mucha bibliografía y comprenderla, utilizar el diccionario, efectuar una búsqueda documental, crear un índice, usar la biblioteca y herramientas informáticas, y leer cuadros estadísticos y gráficos, entre otros. (Ezcurra, 2011, p. 62)

Por lo tanto, la educación superior tiene grandes retos para alcanzar el objetivo 4 propuesto en la agenda 2030, que se ha complejizado aún más con los efectos de la Pandemia del COVID-19, que ha venido a profundizar las brechas de desigualdad social en América 
Latina, como lo indica Salama (2021), una región donde ya existían grandes desigualdades sociales (2021, p. 165).

\subsection{Permanencia en la educación superior y la pandemia del COVID-19}

En la coyuntura de la Pandemia del COVID-19 la población estudiantil universitaria, al igual que toda la población mundial, ha tenido que enfrentar, como consecuencia de las medidas sanitarias, el confinamiento, el aislamiento social, la imposibilidad de alcanzar las metas propuestas y transformar, de un día a otro, la vida cotidiana. Lo que, a su vez, ha generado desesperanza, temor, estrés, ansiedad, en fin, un sin número de trastornos emocionales que influyen de manera directa en el logro de la productividad académica y laboral, así como en las relaciones familiares e interpersonales. En un estudio realizado por Broche-Pérez, Fernández-Castillo y Reyes (2021) se señala que el tener entre 16 y 24 años de edad es una variable predictora para presentar reacciones psicológicas negativas ante la cuarentena y el aislamiento social.

Los mayores efectos los han enfrentado las poblaciones menos favorecidas de la sociedad que, además de lo descrito en el párrafo anterior, no cuentan con los recursos necesarios de satisfacción de las necesidades básicas como consecuencia de la disminución de las jornadas laborales, la pérdida del empleo y el cierre de los centros labores.

Ante las medidas sanitarias para enfrentar el COVID-19, las autoridades universitarias a nivel mundial deciden desarrollar el año lectivo 2020 por medio de clases remotas (Unesco, Instituto Internacional para la Educación Superior en América Latina y el Caribe (lesalc), 2020), es decir, se imparten las lecciones que se habían preparado para el aula física en medios o plataformas digitales (Camacho, 2020). A pesar de ser una medida para salvaguardar la vida, esta decisión conlleva, también, un impacto negativo en el bienestar físico y psicológico debido a la pérdida de hábitos, rutinas y el estrés psicológico, como lo señala un estudio de Wang, Pan et al., citado en Balluerka et al., 2020. El bienestar físico se ve afectado por "malos hábitos alimenticios, patrones de sueño irregulares, sedentarismo y mayor uso de las pantallas" (Balluerka et al, 2020, p. 6)

Las autoridades de universidades de América Latina, en un diálogo virtual promovido por el Banco Interamericano de Desarrollo (2020), reconocen que las clases que se imparten con modalidad remota, estrategia desarrollada ante la Pandemia, afectan con mayor impacto a la población estudiantil que proviene de hogares más desfavorecidos de la sociedad, ya que deben enfrentar la brecha digital, limitaciones en el acceso a las tecnologías y la carencia de 
espacios adecuados en sus hogares para realizar las labores académicas, sumado a la afectación psicológica del confinamiento que "impacta la capacidad de aprendizaje de los estudiantes" (p.3).

A partir de los aportes anteriores, se podría afirmar que las limitaciones que tiene la población estudiantil para enfrentar las clases remotas, como la brecha digital, la falta de acceso a la tecnología, la carencia de espacios para labores académicas y los efectos psicológicos, durante la pandemia COVID-19, son factores que afectan el desempeño académico, y por ende, la permanencia en la educación.

La permanencia en la educación superior es el proceso o trayectoria que sigue la población estudiantil desde el ingreso a una carrera y a un plan de estudios hasta su conclusión, que culmina con la graduación (Solórzano, Regueyra, Arias y Esquivel, 2020). Por lo tanto, el tiempo de permanencia en la universidad está determinado por el plan de estudios de cada carrera.

Diversos autores coinciden en la multicausalidad de factores que influyen en la permanencia o su contracara, la no continuación, los cuales se pueden agrupar en factores académicos, institucionales, socioeconómicos e individuales, y que tienen manifestaciones específicas según la carrera y la universidad. (Espinosa-Castro, Hernández-Lalinde y Mariño Castro, 2020; Neira, 2020; Ordaz y García, 2018; Solórzano et al., 2020).

Las clases presenciales a las que estaba acostumbrada la población estudiantil tienen una centralidad en la figura del docente, mientras que la modalidad remota tiene la centralidad en la capacidad de autorregulación de cada estudiante, por lo que este cambio en la modalidad de enseñanza afecta, en mayor grado, a los sectores socialmente desfavorecidos, y se convierte en un desafío para la población docente, ya que como lo señala García y Bustos, 2021 "se relaciona con formas de aprendizaje académico independientes y con el manejo de acciones estratégicas para la solución de problemas y el ajuste de las tareas y metas en las condiciones educativas asumidas" (p.9).

La autorregulación "es el proceso por el cual cada estudiante puede gestionar sus cogniciones, comportamientos y emociones para mejorar su capacidad y eficiencia asociada al rendimiento académico esperado" (Zambrano-Matamala, Díaz-Mujica, Pérez-Villalobos y Rojas Díaz, 2020, p. 224). Autores como Navea, (2018), Torrano, Fuentes y Soria, (2017), Vives, Durán, Varela y Fortoul (2014), coinciden en que la autorregulación en la población estudiantil conlleva a la autonomía para aprender, la motivación para actuar y la capacidad para implementar acciones para el logro de las metas propuestas. Por lo tanto, la 
autorregulación es un factor que favorece o limita la permanencia de la población estudiantil en las instituciones de educación superior, ya que la población estudiantil con capacidad de autorregulación tiene mayores fortalezas y recursos para continuar con la formación superior mediante las clases remotas.

En esta época de pandemia y de educación remota se espera que la población docente oriente sus esfuerzos a favorecer el desarrollo de la autorregulación de la población estudiantil, a fin de que permanezca en el sistema educativo y no se deteriore su salud física y mental. La población docente, comenta García y Bustos (2021), es reconocida por la población estudiantil “...como un modelo necesario para el enfrentamiento de situaciones críticas como ha sido la pandemia y, como consecuencia, el guía para favorecer el tránsito hacia la autorregulación..." (p. 12).

Señalan Unesco e lesalc que las instituciones de educación superior deben orientar las acciones durante la pandemia, y posterior a ella, a salvaguardar los principios orientadores de la educación superior, como son el "asegurar el derecho a la educación superior de todas las personas en un marco de igualdad de oportunidades y de no-discriminación" así como "no dejar a ningún estudiante atrás" (Unesco e lesalc, 2020, p. 10), lo que concuerda con los objetivos de Desarrollo Sostenible de Naciones Unidas.

\subsection{Universidad de Costa Rica y Pandemia COVID-19}

La UCR es una institución de educación superior, humanista y democrática, como se indica en su Estatuto Orgánico, y asume como principios orientadores, según el Artículo 4: Derecho a la Educación superior, Excelencia académica e igualdad de oportunidades, Libertad de cátedra, Respeto a la diversidad de étnica y cultural, Respeto a las personas y a la libre expresión, Compromiso con el medio ambiente, Acción universitaria planificada y Derecho a la resolución alterna de conflictos (UCR, 2005).

Desde su creación, la UCR ha fomentado la incorporación de estudiantes de diversos sectores sociales para que realicen los estudios universitarios, y desde el 7 de junio de 1956, inicia con los primeros esfuerzos para otorgar becas y favorecer la permanencia y graduación. Este esfuerzo se logra consolidar con la creación, en los años 70, de la Vicerrectoría de Vida Estudiantil y la Oficina de Becas y Atención Socioeconómica, lo cual favorece la igual y la equidad de oportunidades en la población estudiantil (Regueyra, 2010, p. 4). 
Para el I ciclo del año 2020, el 54,74\% de la población matriculada en la UCR disfrutó de una categoría de beca por condición socioeconómica (UCR, 2021), lo que evidencia su compromiso de favorecer la equidad.

A inicios del mes de marzo de 2020, en Costa Rica aparece el primer caso confirmado por COVID-19, e inician las medidas sanitarias emitidas por el Ministerio de Salud y la Comisión Nacional de emergencias a fin de evitar el contagio. El 16 de marzo del 2020, el presidente de la República, por medio del decreto ejecutivo 42227-MP-S declara la emergencia nacional del COVID-19 y la suspensión de lecciones en todos los centros educativos públicos y privados (Alvarado, Lara y Salas, 2020).

Por su parte, la Universidad de Costa Rica activó la creación del Centro de Coordinación Institucional de Operaciones ( $\mathrm{CCIO}$ ) como autoridad máxima para definir y orientar acciones en casos de emergencia. Esta instancia, por medio del comunicado 3 del 11 marzo del 2021, suspende actividades presenciales en la UCR, y solicita "al personal docente suspender, a partir de este momento, las clases presenciales e implementar una modalidad de enseñanza virtual que garantice la continuidad y calidad" (UCR, 2020a, p. 1)

Con la misma fecha del 11 de marzo de 2020, el CCIO mediante el comunicado 5, indica a la población estudiantil que las clases se impartirán a partir de esa fecha de manera virtual por medio de la plataforma de Mediación Virtual, y se detallan las acciones que deben realizar para ingresar a cada uno de los cursos matriculados (UCR, 2020b).

Mediación Virtual es la plataforma creada por la UCR y establecida desde el año 2009 para gestionar los entornos virtuales utilizados en las actividades académicas y promover el acceso a las tecnologías de información y comunicación (Kikut, 2020). A pesar de contar con este recurso, antes de la Pandemia no era utilizada por toda la población docente, sin embargo, ante la suspensión de las clases presenciales se promovió la capacitación y asesoría para que toda la población académica utilizara este entorno como el espacio institucional para desarrollar sus actividades (Kikut, 2020).

La UCR crea el sitio web denominado Así es como la UCR afronta el nuevo coronavirus donde se colocan los lineamientos institucionales y nacionales para enfrentar la pandemia del COVID-19 (UCR, 2020), las resoluciones sobre las acciones que definen las autoridades universitarias, así como directrices e información general sobre la pandemia y estrategias de prevención.

Con el propósito de atender la demanda de internet en la Universidad causada por el trabajo y las clases de manera remota, el Centro de Informática de la UCR coordina con el 
Instituto Costarricense de Electricidad (ICE) para duplicar el ancho de banda de internet en todas las sedes, y con el Comunicado 6, la UCR informa sobre las actividades que está realizando a fin de fortalecer las plataformas tecnológicas para virtualizar sus actividades (UCR, 2020c).

Con la resolución 158-2020, la Rectoría de la UCR (Araya, 2020a) indica que, para el II ciclo 2020, las actividades académicas continúan de manera virtual por medio de la Plataforma Mediación Virtual u otro recurso o herramienta tecnológica.

Como una medida para favorecer la permanencia y equidad en la población estudiantil, el 11 de mayo del 2020, la UCR entrega, para las clases remotas y en calidad de préstamo, las primeras 750 tabletas con chip de acceso a internet a la población estudiantil con beca por condición socioeconómica y con beneficios complementarios (Araya, 2020b).

\section{Metodología}

\subsection{Enfoque}

La investigación se desarrolla bajo el enfoque cuantitativo, se propone medir los efectos de la pandemia en la permanencia de la población estudiantil participante. Para el análisis de los datos se utilizan las técnicas de la estadística descriptiva con alcance exploratorio, ya que este estudio representa el primer acercamiento al objeto de estudio y no se pretende realizar inferencias estadísticas. La información se recopiló entre diciembre de 2020 y enero de 2021, por lo que también es un estudio de carácter transversal.

\subsection{Unidades de análisis}

La unidad de análisis la conforma la población estudiantil de 10 carreras que se imparten en la Sede Rodrigo Facio de la Universidad de Costa Rica y forman parte del Proyecto de seguimiento a la permanencia de la población estudiantil: Educación Especial, Orientación, Administración Pública, Administración Aduanera y Comercio Exterior, Psicología, Computación, Enfermería, Microbiología y Química Clínica, Asistente de Laboratorio y Farmacia.

En la consulta participaron 974 estudiantes que respondieron el cuestionario de manera voluntaria, por lo que la selección de las personas participantes se realizó por un muestreo no probabilístico. Por ende, los resultados no se pueden generalizar.

De la población participante, 36,5\% son del área de Salud, 36,3\% del área de Ciencias Económicas, $11,9 \%$ del área de Ciencias Sociales, 11,8\% del área de Educación y 3,5\% del área de Ingeniería (Tabla1). 
Tabla 1. Frecuencia y porcentaje de estudiantes por área de carrera a la que pertenecen, UCR, 2020

\begin{tabular}{|l|r|r|}
\multicolumn{1}{|c|}{$\begin{array}{c}\text { Área de la } \\
\text { carrera }\end{array}$} & $\begin{array}{r}\text { Frecuencia } \\
\text { Salud }\end{array}$ & Porcentaje \\
\hline Económicas & 355 & 36,5 \\
\hline Sociales & 354 & 36,3 \\
\hline Educación & 116 & 11,9 \\
\hline Ingeniería & 115 & 11,8 \\
\hline Total & 34 & 3,5 \\
\hline
\end{tabular}

Fuente: Elaboración propia con los datos recolectados, 2020.

\subsection{Recolección de la información}

La recolección de información se realizó por medio de la técnica de encuesta, utilizada comúnmente en los estudios de índole cuantitativa, con la aplicación de un cuestionario que contenía en su mayoría preguntas cerradas. Sin embargo, se consideran dos preguntas abiertas para conocer las necesidades y sugerencias de la población estudiantil.

Además, para identificar el nivel de afectación y cambios de la pandemia con respecto a la situación académica, socioeconómica y salud, se utilizó la escala tipo Likert con las siguientes categorías: Nada, poco, moderadamente, bastante y mucho. Se aplican tres escalas, una escala para medir el nivel de afectación en la actividad académica conformada por 12 ítems ( $\alpha=0,821)$; otra escala que mide el nivel de afectación socioeconómica propia del estudiante y del hogar, constituida por 5 ítems ( $\alpha=0,857)$ ]; y una escala que mide el nivel de afectación en la salud mental y física, con 7 ítems $(\alpha=0,825)$. Las tres escalas presentan índices de confiabilidad (Alfa de Cronbach) aceptables, por lo que los ítems presentan consistencia en la medición.

Las variables seleccionadas para la investigación se detallan en la Tabla 2: 
Tabla 2. Descripción de las dimensiones, variables del estudio y alfa de Cronbach de las escalas del estudio, UCR, 2020

\begin{tabular}{|c|c|c|}
\hline Dimensión & Variables & Alfa de Cronbach \\
\hline $\begin{array}{lr}\text { Tenencia } & \text { de } \\
\text { dispositivos } & \text { y } \\
\text { acceso a internet } & \end{array}$ & $\begin{array}{l}\text { - Tenencia de dispositivos } \\
\text { - Conexión a internet en el hogar } \\
\text { utilizada para las clases remotas } \\
\text { - Velocidad y percepción de la calidad } \\
\text { de la conexión a internet } \\
\text { - Dispositivos utilizados para labores } \\
\text { académicas }\end{array}$ & $\begin{array}{l}\text { Esta dimensión no } \\
\text { contempla escalas. }\end{array}$ \\
\hline Académica & $\begin{array}{l}\text { - Permanencia } \\
\text { - Percepción del rendimiento académico } \\
\text { - Dificultades enfrentadas durante los } \\
\text { ciclos I y II, 2020, que afectan el } \\
\text { desarrollo académico } \\
\text { - Intención de matrícula para el I ciclo } \\
2021 \\
\text { - Necesidades para la matricula del I } \\
\text { ciclo } 2021\end{array}$ & $\begin{array}{l}\text { Escala nivel de afectación } \\
\text { en la actividad } \\
\text { académica, conformada } \\
\text { por } 12 \text { ítems }(\alpha=0,821) \text {. }\end{array}$ \\
\hline $\begin{array}{l}\text { Socioeconómica, } \\
\text { personal y del hogar }\end{array}$ & $\begin{array}{l}\text { - Situaciones socioeconómicas } \\
\text { generadas por la Pandemia COVID-19 } \\
\text { - Tenencia de beca en la Universidad } \\
\text { - Situaciones socioeconómicas y lo } \\
\text { personales que afectaron el } \\
\text { desempeño académico durante los } \\
\text { ciclos I y II, } 2020\end{array}$ & $\begin{array}{l}\text { Escala nivel de afectación } \\
\text { socioeconómica propia y } \\
\text { del hogar, constituida por } \\
5 \text { ítems }(\alpha=0,857) \text {. }\end{array}$ \\
\hline Salud mental y física & $\begin{array}{l}\text { - Situaciones de salud física o mental } \\
\text { generadas por la Pandemia COVID-19 } \\
\text { - Situaciones de salud física o mental } \\
\text { que afectaron el desempeño } \\
\text { académico durante los ciclos I y II, } \\
2020\end{array}$ & $\begin{array}{l}\text { Escala nivel de afectación } \\
\text { en la salud mental y física, } \\
\text { con } 7 \text { ítems }(\alpha=0,825) \text {. }\end{array}$ \\
\hline
\end{tabular}

Fuente: Elaboración propia, 2021.

Para el proceso de recolección de la información, desde cada carrera, se invitó a la población estudiantil para que de manera voluntaria respondiera el cuestionario.

Cada carrera utilizó diversas estrategias para invitar a la población estudiantil a llenar el cuestionario colocado en la WEB como mensajes por correo electrónico y redes sociales, coordinaciones con asociaciones de estudiantes de cada carrera, entre otros. Se realizaron dos convocatorias, una en el mes de diciembre de 2020 y la otra durante la primera y segunda semana de enero 2021.

La encuesta fue autoadministrada por cada estudiante que ingresó de manera voluntaria a la dirección electrónica que se le envió. Se utilizó la plataforma de encuestas en línea LimeSurvey para la recolección de la información. 
En la introducción de la encuesta se informó de los objetivos y alcances de la investigación, así como de los compromisos asumidos por el equipo de investigación relacionados con la confidencialidad de la información. La población estudiantil al responder la encuesta da su consentimiento para que cada carrera procese la información y la utilice para tomar las decisiones correspondientes.

En la investigación se garantiza la seguridad de los datos de carácter personal del estudiantado y se da un manejo discreto, privado y confidencial rigiéndose por las regulaciones estipuladas en la legislación costarricense en general y por las de la Universidad de Costa Rica de manera particular, según la normativa vigente ${ }^{5}$.

\subsection{Procesamiento de la información}

Para el procedimiento de análisis de los datos, se realizó un análisis estadístico descriptivo (tablas y visualización). Para ello se utilizaron las herramientas de software Microsoft Office Excel 365 versión 2104, Statistical Package for the Social Sciences (SPSS) versión 23 y Power BI Desktop versión 2.92.706.0.

La información se procesó de manera agrupada para toda la población que respondió el cuestionario. Entre los análisis estadísticos que se realizaron se encuentran la elaboración de frecuencias absolutas y relativas para cada una de las variables, asimismo se realizaron tablas de contingencia entre las variables. Posteriormente, se visualiza por medio de gráficos estadísticos.

Adicionalmente, para el procesamiento de las opiniones brindadas por la población estudiantil, en las preguntas abiertas, se elaboraron categorías y se agruparon las opiniones según la similitud de las necesidades o sugerencias con la categoría.

\section{Resultados}

\subsection{Población encuestada}

El cuestionario fue respondido por un total de 974 estudiantes. El 14,4\% de estudiantes de primer año, el $24.2 \%$ y $24.1 \%$ de la población estudiantil encuestada cursaba el segundo y tercer año de carrera respectivamente, $17,8 \%$ son estudiantes de cuarto año y $11,6 \%$ de quinto año de carrera.

\footnotetext{
${ }^{5}$ Regulaciones nacionales: Ley N. ${ }^{\circ}$ 8968: Protección de la persona frente al tratamiento de sus datos personales y su Reglamento Decreto Ejecutivo N. ${ }^{\circ}$ 37554-JP. Regulaciones de la Universidad de Costa Rica: Resoluciones VI1894-2015 y VI-2734-2015 de la Rectoría y la Vicerrectoría de Investigación y para el proyecto en específico el Oficio ViVE-142-2013, de la Vicerrectoría de Vida Estudiantil donde emite criterio en relación con el acceso y manejo de la información para el proyecto.
} 
El 63\% de las personas participantes cuentan con algún tipo de beca asignada por la Oficina de Becas de la Universidad de Costa Rica. De la población becada, el 83\% tiene beca por condición socioeconómica y el $29 \%$ disfruta beca de estímulo. El 15\% disfruta de ambas becas.

En relación con la categoría de beca por condición socioeconómica ${ }^{6}$, el $57 \%$ disfruta de beca 5 , que tiene la mayor cantidad de beneficios, como la exoneración de matrícula y la ayuda económica (Figura 1). La categoría de beca es un excelente indicador del nivel socioeconómico de las familias de donde proviene la población estudiantil. Dicha beca se asigna a partir un índice socioeconómico construido por la Oficina de Becas, el cual se actualiza cada año.

\section{Figura 1.}

Porcentaje de estudiantes por tipo de categoría de beca que posee, UCR, 2020

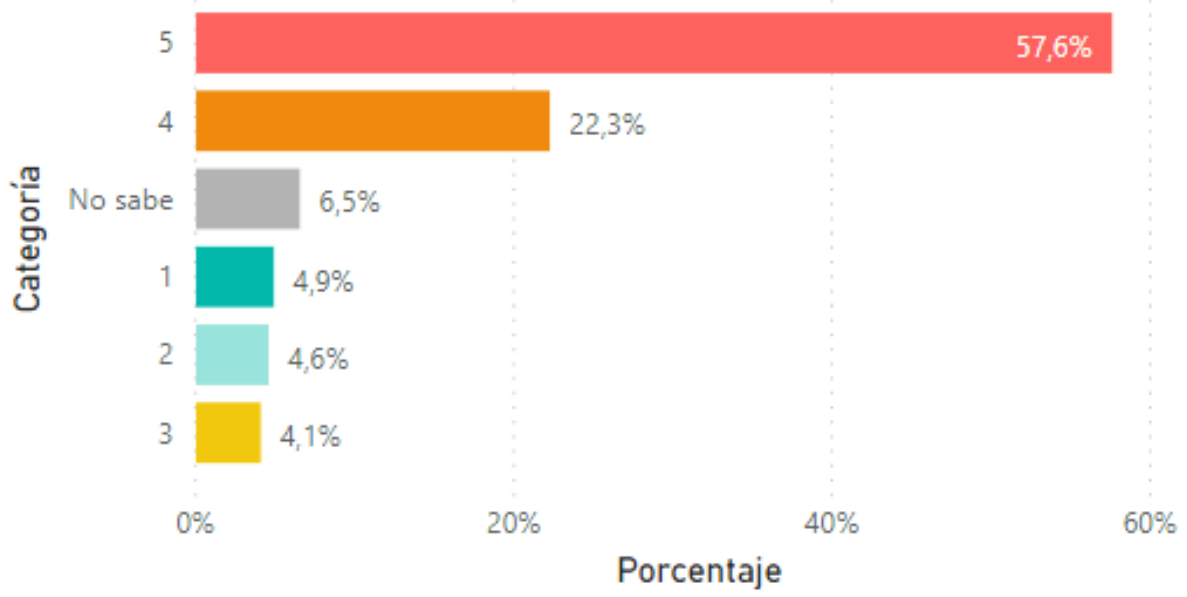

Fuente: Elaboración propia con los datos recolectados, 2020.

\subsection{Recursos y limitaciones que tiene la población estudiantil relacionados con dispositivos y conectividad a internet para labores académicas}

\subsubsection{Dispositivos para el acceso a clases remotas}

El $20 \%$ de la población estudiantil encuestada cuenta en su hogar con computadora de escritorio, un $94 \%$ con computadora portátil, un 30\% con tableta y un $99 \%$ cuenta con teléfono celular. El $60 \%$ de los hogares de las personas encuestadas cuentan con dos dispositivos, el $30 \%$ cuentan con 3 , el $8 \%$ con cuatro y el $2 \%$ de los hogares cuentan con un único dispositivo.

\footnotetext{
6 Se asigna con fundamento en la condición socioeconómica determinada por la Oficina de Becas y Atención Socioeconómica según el índice socioeconómico. A cada categoría de beca le corresponde un porcentaje de exoneración sobre el costo de matrícula y disfrute de beneficios complementarios según lo estipula el Reglamento de adjudicación de Becas a la población estudiantil.
} 
Los dispositivos más utilizados para recibir las clases remotas son la computadora portátil y el teléfono celular con $86 \%$ y $57 \%$ respectivamente. Un $14 \%$ utiliza tableta y un $11 \%$ computadora escritorio. Importante resaltar que un total de 18 estudiantes cuentan únicamente con un celular para conectarse a las clases remotas.

El $91 \%$ de las personas indican que el dispositivo que utilizan para las clases remotas es propio del hogar, el restante $9 \%$ es prestado, alquilado u otro. El 19\% lo debe compartir con otra persona y el $8 \%$ lo comparte con dos más. El $74 \%$ indica que es de uso exclusivo.

El $83 \%$ de la población estudiantil encuestada debió realizar adaptaciones a los dispositivos para acceder a clases remotas (35\% moderadas, el $26 \%$ pocas, $14 \%$ bastante y un $8 \%$ muchas). El $17 \%$ no tuvieron que adaptar los dispositivos para acceder a las clases remotas.

El $75 \%$ de la población-enfrentó dificultades relacionadas con el acceso a programas informáticos o software para realizar las tareas proyectos o exámenes (35\% poco, 25\% moderado, $10 \%$ bastante y $5 \%$ mucho). El $25 \%$ de la población no enfrentó limitaciones relacionados con programas informáticos o software para realizar las tareas proyectos 0 exámenes.

\subsubsection{Conectividad a internet}

El $33 \%$ de la población estudiantil indica que en sus hogares cuentan con internet alámbrica, $80 \%$ cuenta con datos móviles y un $91 \%$ tiene internet inalámbrica.

Para el $92,5 \%$ de la población, el servicio de internet es propio del hogar, el restante $7,5 \%$ lo alquila, se lo prestan, utiliza servicio público u otro. Un total de 10 estudiantes no cuenta en el hogar con conexión a internet. El 20\% cuenta con un solo tipo de conexión y un $79 \%$ posee en el hogar con 2 o 3 conexiones a internet.

La conexión a internet que utilizan para las clases remotas fue calificada como buena, muy buena y excelente por el $60 \%$ de la población encuestada y un $40 \%$ la califica como regular, mala y muy mala.

El 95\% de la población encuestada indica que enfrentó problemas de conectividad a internet (35\% moderado, 25\% poco, 24\% bastante y un 11\% mucho). El 48\% de la población estudiantil debió aumentar la velocidad de internet para las clases remotas 


\subsection{Consecuencias de la pandemia en el avance académico, condición} socioeconómica y desarrollo personal físico y mental de la población estudiantil

\subsubsection{Efectos en el avance académico}

Para el $28,7 \%$ de las personas encuestas el rendimiento académico en I y II ciclo del 2020 disminuyó, para un $24,8 \%$ aumentó y para el $46,4 \%$ se mantuvo igual. Al comparar la percepción sobre el rendimiento académico durante dicho periodo de la población con beca y la población no becada se observa un comportamiento similar como se aprecia en la figura 2 .

\section{Figura 2.}

Porcentaje de estudiantes por tenencia de beca según su percepción del rendimiento académico durante la pandemia, UCR, 2020.

Rendimiento académico Aumentó Đ Disminuyó OSe mantuvo igual que otros años

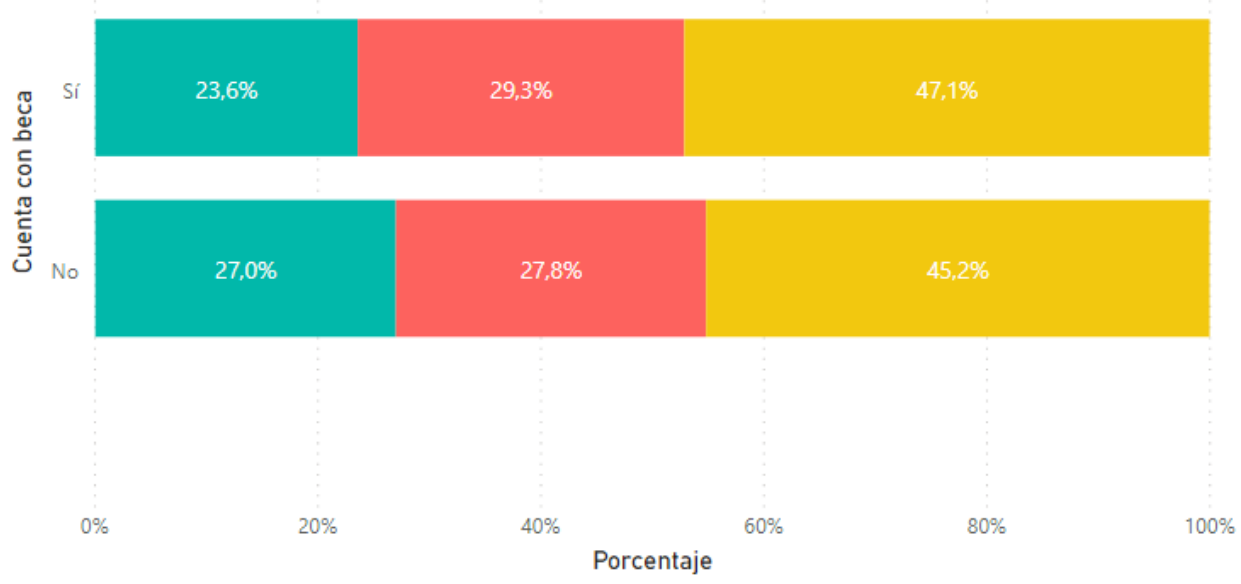

Fuente: Elaboración propia con los datos recolectados, 2020.

La afectación de la pandemia a nivel académico, según la población encuestada se manifiesta en que el $46 \%$ disminuyó la carga académica debido a las clases remotas y el $20 \%$ retiró o abandonó algún curso. Además, 83\% enfrentó dificultades para cumplir con la evaluación de los cursos, $66 \%$ de la población indica rezago en el cumplimiento del programa de los cursos y $41 \%$ de la población indica que se vio afectada porque la unidad académica no ofreció cursos del plan de estudios ante la pandemia del COVID-19.

Las personas encuestadas enfrentaron dificultades en las clases remotas, $91 \%$ señala que enfrentó dificultades personales para adaptarse a las clases remotas, 9\% no enfrentó dificultades personales para adaptarse a este tipo de clases, 95\% indica que enfrentó 
dificultades para adaptarse al proceso de enseñanza aprendizaje empleado por docentes en esta modalidad, $88 \%$ enfrentó dificultades de interacción en los trabajos grupales con las compañeras y compañeros de los cursos y $91 \%$ percibe que la población docente tuvo dificultades para adaptar las clases a modalidad remota (Tabla 3)

El 95,27\% indica que la Unidad Académica ha apoyado a la población estudiantil ante la situación de la pandemia COVID-19 (38,5\% moderado, 28,54\% bastante, $20,02 \%$ poco y $8,21 \%$ mucho).

Tabla 3. Distribución porcentual del estudiantado por aspectos académicos y dificultades presentadas durante la pandemia según nivel de afectación, UCR, 2020.

Aspectos académicos y dificultades Mucho Bastante Moderada Poco Nada Total

\section{Procesos académicos}

Rezago en el cumplimiento del programa de los cursos

Cumplir con la evaluación de los cursos

Unidad académica no ofreció cursos del plan de estudios

Disminución de la carga académica

\section{Clases remotas}

Dificultades para adaptarse al proceso de enseñanza aprendizaje empleado por alguna de las personas docentes

Dificultades personales para adaptarse a las clases

Dificultades de interacción en los trabajos grupales con las compañeras y compañeros de los cursos

Problemas con la conectividad a internet Población docente tuvo dificultades para adaptar las clases a modalidad remota Adaptar los dispositivos para acceder a clases

Fuente: Elaboración propia con los datos recolectados, 2020.

\begin{tabular}{|r|r|r|r|r|r|}
\hline 10.0 & 11.0 & 23.0 & 21.0 & 34.0 & 100.0 \\
\hline 8.0 & 17.0 & 33.0 & 25.0 & 17.0 & 100.0 \\
\hline 2.0 & 7.0 & 13.0 & 15.0 & 59.0 & 100.0 \\
\hline 21.0 & 29.0 & 31.0 & 14.0 & 5.0 & 100.0 \\
\hline 16.0 & 20.0 & 36.0 & 19.0 & 9.0 & 100.0 \\
\hline 16.0 & 20.0 & 29.0 & 23.0 & 12.0 & 100.0 \\
\hline 11.0 & 24.0 & 35.0 & 25.0 & 5.0 & 100.0 \\
\hline 10.0 & 22.0 & 39.0 & 20.0 & 8.0 & 100.0 \\
\hline 8.0 & 14.0 & 35.0 & 26.0 & 17.0 & 100.0 \\
\hline
\end{tabular}

\subsubsection{Consecuencias de la pandemia en la condición económicas y social de las} familias de la población estudiantil.

En relación con los efectos de la Pandemia COVID-19, el 57\% de la población encuestada indica que en el hogar han tenido dificultades económicas. La población becada ha sido más afectada, que la población no becada, ya que el $69 \%$ de los becados indica que han tenido dificultades económicas, mientras que el $38 \%$ de los estudiantes no becados responde que han tenido afectación (figura 3). 
Figura 3.

Porcentaje de estudiantes por tenencia de beca y dificultades económicas en su hogar durante la pandemia, UCR, 2020.

Dificultades económicas @ No

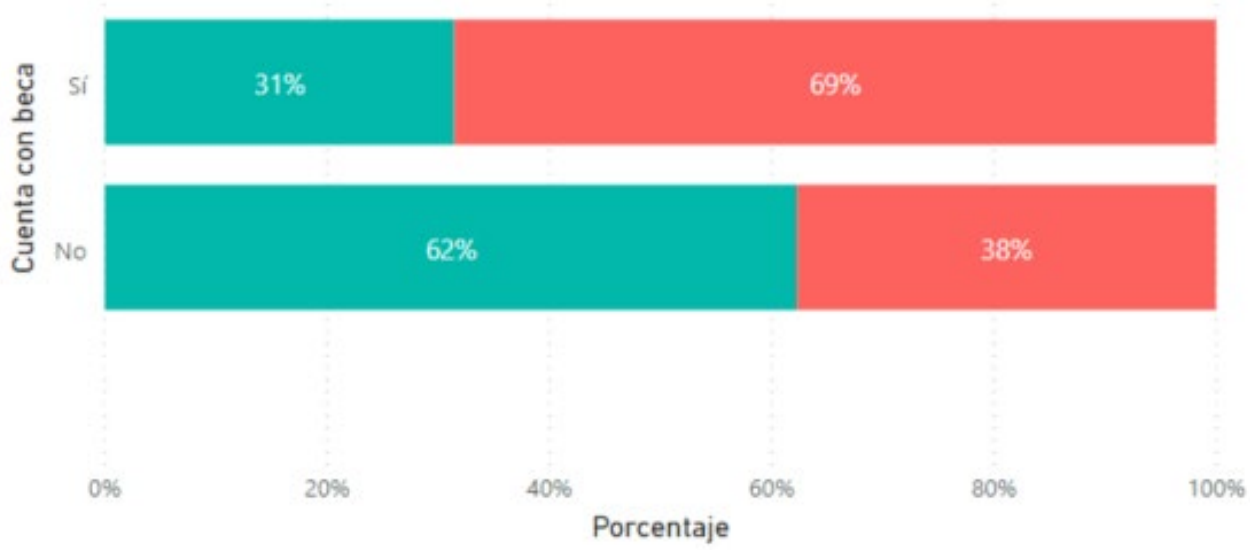

Fuente: Elaboración propia con los datos recolectados, 2020.

En relación con el área económica, (Tabla 4), el 52\% de las personas encuestadas o algún miembro de la familia ha enfrentado problemas de desempleo, $66 \%$ ha enfrentado reducción de jornada laboral, $77 \%$ ha tenido reducción de los ingresos, $62 \%$ indica que algún miembro de la familia ha tenido problemas con el pago de deudas, y el $84 \%$ ha tenido gastos adicionales e inusuales relacionados con la Pandemia COVID-19.

Tabla 4. Distribución porcentual del estudiantado por dificultades económicas presentadas durante la pandemia según nivel de afectación, UCR, 2020.

\begin{tabular}{|l|c|c|c|c|c|c|}
\hline \multicolumn{1}{|c|}{ Dificultades económicas } & Mucho & Bastante & Moderada & Poco & Nada & Total \\
\hline Reducción de ingresos & 18 & 21 & 24 & 14 & 23 & $\mathbf{1 0 0}$ \\
\hline Situación de desempleo & 16 & 10 & 13 & 13 & 48 & $\mathbf{1 0 0}$ \\
\hline Reducción de jornada laboral & 14 & 17 & 21 & 14 & 34 & $\mathbf{1 0 0}$ \\
\hline $\begin{array}{l}\text { Dificultad en el pago de deudas o } \\
\text { préstamos }\end{array}$ & 14 & 11 & 18 & 19 & 38 & $\mathbf{1 0 0}$ \\
\hline $\begin{array}{l}\text { Gastos adicionales e inusuales en } \\
\text { relación con la pandemia }\end{array}$ & 12 & 19 & 29 & 24 & 16 & $\mathbf{1 0 0}$ \\
\hline
\end{tabular}

Fuente: Elaboración propia con los datos recolectados, 2020.

En cuanto a la situación socioeconómica es necesario prestar atención a la población estudiantil que no cuenta con beca por parte de la Oficina de Becas, ya que como consecuencia de la Pandemia del COVID-19, las condiciones socioeconómicas del hogar 
desmejoraron y esta población no becada podría requerir algún tipo de beca institucional para poder continuar con los estudios universitarios.

4.3.3 Consecuencias de la pandemia en el desarrollo personal físico y mental de la población estudiantil

La población estudiantil que respondió la encuesta señala algún nivel de afectación psicosocial, como: estrés (98\%), sentimientos de frustración ante la pandemia (95\%), ansiedad (95\%), sentimientos de inseguridad (95\%), depresión (79\%), disminución la actividad física $(87 \%)$ y problemas de alimentación o nutrición (71\%) (Tabla 5).

Tabla 5. Distribución porcentual del estudiantado por aspectos de salud física y mental presentados durante la pandemia según nivel de afectación, UCR, 2020.

\begin{tabular}{|l|c|c|c|c|c|c|}
\hline \multicolumn{1}{|c|}{$\begin{array}{c}\text { Aspectos salud física y } \\
\text { mental }\end{array}$} & Mucho & Bastante & Moderada & Poco & Nada & Total \\
\hline Estrés & 51 & 30 & 13 & 4 & 2 & $\mathbf{1 0 0}$ \\
\hline Sentimientos de frustración & 42 & 25 & 19 & 9 & 5 & $\mathbf{1 0 0}$ \\
\hline Disminución actividad física & 42 & 19 & 17 & 9 & 13 & $\mathbf{1 0 0}$ \\
\hline Ansiedad & 37 & 29 & 20 & 9 & 5 & $\mathbf{1 0 0}$ \\
\hline Sentimientos de inseguridad & 34 & 27 & 21 & 13 & 5 & $\mathbf{1 0 0}$ \\
\hline Depresión & 17 & 14 & 23 & 25 & 21 & $\mathbf{1 0 0}$ \\
\hline $\begin{array}{l}\text { Problemas de alimentación } \\
\text { nutrición }\end{array}$ & 15 & 14 & 21 & 21 & 29 & $\mathbf{1 0 0}$ \\
\hline
\end{tabular}

Fuente: Elaboración propia con los datos recolectados, 2020.

Se puede afirmar que la población estudiantil encuestada ha enfrentado, durante la pandemia, afectación psicosocial preocupante, ya que presenta porcentajes altos de estrés, sentimientos de frustración ansiedad, inseguridad y depresión, lo que amerita la construcción de propuestas urgentes, por parte de las autoridades de salud a fin dotar a la población estudiantil de herramientas para enfrentar estas situaciones y alcanzar el equilibrio psicosocial y no afecte su permanencia.

\subsection{Intención de matrícula de la población estudiantil en el I ciclo 2021}

El $84 \%$ de la población encuestada indica que matriculará cursos en el I ciclo del 2021 , $12 \%$ aún no lo ha decidido y el $4 \%$ que, en el momento de participar en la investigación, ya había tomado la decisión de no matricular. En el tiempo que se desarrolló la investigación, la UCR no había indicado si el I ciclo lectivo 2021 se implementaría de manera remota o presencial. 
En el supuesto de que en el I ciclo 2021 las lecciones se realizaran de manera remota, el $61 \%$ de la población encuestada indica que matricularía todos los cursos que le corresponde según el plan de estudios, el $34 \%$ solo parte de los cursos y el $5 \%$ definitivamente no matricularía.

Las razones que expone la población para matricular de manera parcial o ningún curso son: ajuste a las clases remotas (46\%), dificultades personales para adaptarse al aprendizaje remoto $(40 \%)$, por motivos laborales $(30 \%)$, debe asumir tareas de apoyo familiar $(28 \%)$, horario de los cursos (17\%), problemas de acceso remoto (14\%), experimenta problemas de salud originados por la Pandemia (13\%) y menciona que no puede asumir los costos de los estudios (7\%).

\subsection{Discusión de resultados}

Como se observa en la información aportada por la población estudiantil encuestada, la Pandemia COVID-19 afectó de manera distinta a la población estudiantil. La Universidad de Costa Rica siendo una universidad pública estatal tiene entre la población estudiantil representación de los diferentes sectores económicos y sociales que configuran el país, producto de los esfuerzos realizados para garantizar la equidad en el acceso a la educación superior de sectores tradicionalmente excluidos.

En un estudio realizado por Gutiérrez y Kikut, para "calcular y validar un índice de posibilidades socioeconómicas del estudiantado matriculado en el primer semestre de 2019 en las universidades estatales" (2020, p. 5), se muestra que para la Universidad de Costa Rica hay población estudiantil que se ubica en cada uno de los 5 quintiles socioeconómicos, pero con diferente grado de representación. La condición de beca por condición socioeconómica y las diferentes categorías de becas según la condición socioeconómica evidencia la composición de la población estudiantil de la UCR (figura 3).

En el I ciclo lectivo del año 2020, según estadísticas de la Oficina de Becas 2021 (UCR, 2021) el 54,10\% de la población estudiantil de la Universidad de Costa Rica disfrutó de beca por condición socioeconómica y de esta población becada, el 73,29\% tenía beca 5 que además de la exoneración total sobre los montos de matrícula, se le otorgó ayuda económica en diversos rubros según cada caso.

Como es de esperar las consecuencias de la pandemia tienen un impacto diferenciado en la población estudiantil según su capacidad de acceso a bienes y servicios. En el $57 \%$ de los hogares de la población estudiantil encuestada se han presentado dificultades económicas, 
el $77 \%$ ha visto reducidos los ingresos y el $86 \%$ han tenido gastos adicionales en el hogar debido a la pandemia. Lo que coincide con lo señalado por la Comisión Económica para América Latina (C) y la UNESCO en el Informe COVID-19 "La pandemia de COVID-19 exacerbó las desigualdades sociales, la inequidad y la exclusión” (Cepal y Unesco, 2020, p.16).

Para lograr continuar con los estudios universitarios de manera remota, la población estudiantil debe tener como mínimo algún dispositivo electrónico y alguna conexión a internet que le permita comunicarse. Cada estudiante, independientemente del sector económico y social debe tener acceso a estos bienes y servicios, ya que como lo indica Amador, "La capacidad adquisitiva es una de las principales barreras a la tecnología. Personas con mayores ingresos tienen mayor facilidad de acceder a la tecnología que aquellas con menores ingresos" (2020, p. 227).

Como se evidenció con los resultados de la investigación existe una gran brecha digital entre la población estudiantil, en forma similar a la que se presenta en la sociedad costarricense, como lo señaló Amador en su informe:

No todas las personas, no todos los hogares, no todos los países, tienen las mismas posibilidades de acceso a la tecnología. La brecha digital no es una, sino muchas, pues hay brechas entre países, entre regiones y entre los habitantes de un país. Hay brechas de acceso a Internet, pero también las hay en capacidad de uso de un teléfono móvil inteligente. Por todo lo anterior, "brecha digital" es un concepto complejo, multidimensional, que conglomera una serie de desigualdades de la era digital (2020, p. 224)

De los 974 estudiantes que participaron en la investigación, un total de 18 estudiantes tienen únicamente un teléfono celular para conectarse a las clases remotas. Frente a otros estudiantes que cuentan con otros dispositivos para uso académico. Esta inequidad se presenta también en el acceso al software que requieren para realizar las tareas, exámenes y proyectos.

Cada uno de los dispositivos mencionados tiene distintos alcances como herramienta en la educación superior que favorece o limita las diversas actividades que implica, siendo la computadora la herramienta ideal. Sin embargo, en Costa Rica indica Amador, la tenencia de este dispositivo ha disminuido en los hogares "es un asunto preocupante, considerando la importancia que estas tienen para la productividad de las personas en todos los ámbitos de la 
vida, desde lo social hasta lo educativo y lo laboral. (2020, p. 254). Esta situación se evidenció con las respuestas de la población entrevistada.

La conectividad a internet, fundamental para las clases remotas, es otro aspecto donde se evidencia la desigualdad. Esta tiene diversas implicaciones en las posibilidades de mantener estudios universitarios que requieren de descarga de datos y mantener, por tiempos prolongados, la conexión en tiempo real; al respecto señala Amador "no es lo mismo contar con una conexión fija que el hacerlo por dispositivos móviles (SIM), entendiendo que los segundos tienen importantes limitaciones de descarga de datos que limitan el acceso a Internet" (2020, p. 252).

La conexión a internet en Costa Rica muestra también disparidad entre las zonas urbanas y rurales lo que se convierte en otra limitante para continuar con estudios universitarios de manera remota (Amador, 2020, p. 265).

Se podría considerar, desde los porcentajes que arrojó la investigación, que la mayoría de la población estudiantil cuenta con dispositivos y conexión a internet, sin embargo, esa mirada encubre la realidad de la población estudiantil que procede de los sectores desfavorecidos de la sociedad costarricense y que tiene, como se mencionó líneas atrás, los porcentajes más bajos de representación en la Universidad de Costa Rica, por lo que carecen de dispositivos y conexión a internet adecuados, para continuar con estudios universitarios de manera remota. Esto a todas luces es inequidad, como lo evidencian las personas encuestadas al manifestar: "Si! No cuento con dispositivos necesarios para afrontar las clases; ..." Estudiante \#1191 "Alguna clase de beca que me ayude a exonerar los créditos, una computadora propia y una buena estabilidad de internet." Estudiante \#463.

La tenencia de las TIC para realizar estudios desde los hogares no asegura que cuenten con el ambiente adecuado para estudiar, ni que las personas tengan las destrezas y habilidades que se requieren para continuar con los estudios por medio de clases remotas, como se evidencia en las respuestas de la población encuestada, el 91\% manifiesta tener dificultades personales para adaptarse al proceso de enseñanza aprendizaje remoto y el 95\% indicó tener dificultades para adaptarse al proceso de enseñanza aprendizaje empleado por alguna de las personas docentes, lo que ha sido señalado también por López y Rodríguez:

En ocasiones, existe una sola computadora en el hogar que se comparte con otros miembros de la familia y muchos de los estudiantes no cuentan con un espacio para sus labores escolares. Además, al estar en casa, el tiempo de que disponen se fragmenta entre diversas actividades, tareas del hogar y el cuidado de otros familiares. A esto se 
suma que, aunque existe la creencia de que estos alumnos pertenecen a la generación tecnológica, muchos de ellos carecen de las habilidades necesarias para desarrollar actividades de aprendizaje de forma virtual, así como de la autodisciplina que demandan estas modalidades, en un ambiente de estrés, incertidumbre y de restricciones socioeconómicas derivadas de la pandemia. (2020, p. 104)

Esto se relaciona con la afirmación de que la brecha digital "es un concepto multidimensional, no es una medición única, sino que hay múltiples aristas en las que se pueden medir las diferencias de uso, acceso y apropiación de las TIC en distintas unidades de medición, como hogares o personas" (Amador, 2020, p. 272).

Las consecuencias de la Pandemia en la permanencia de la población estudiantil universitaria se evidencian en dos niveles, la prolongación en el tiempo para concluir el plan de estudios de la carrera y el no continuar matriculando créditos del plan de estudios.

La prolongación en la permanencia ocurrirá debido a que un 46\% disminuyó la carga académica, un $40 \%$ indica que la unidad académica no impartió los cursos que requería y el $20 \%$ retiró o abandonó algún curso. Situación que se acrecentará más para el I ciclo 2021, ya que el $34 \%$ matriculará solo una parte de los cursos que les corresponde, a lo que refieren dos estudiantes participantes: "La carga académica aumenta con las clases virtuales por lo que es extremadamente pesado tratar de llevar el plan de estudios completo" Estudiante \#424. "Matriculo parte de los cursos porque matricular el bloque completo es demasiada carga académica y estrés que no puedo manejar bien." Estudiante \#563.

En relación con la no continuación de matrícula de cursos del plan de estudios de la carrera, el $4 \%$ de la población encuestada en el momento que se aplicó el cuestionario, ya había decidido no matricular en el I ciclo 2021, porcentaje que podría aumentar, si el 12\%, que aún no había decido, no concreta la matriculará de los cursos del plan de estudios en el I ciclo 2021.

Entre las razones para no matricular o matricular sólo parte de los cursos que le corresponden, se enfatizan: dificultades personales para adaptarse a las clases remotas, por tener que trabajar o por asumir tareas de apoyo familiar. Al respecto, indican: "Dado a la situación económica familiar, este año comencé a trabajar, por lo tanto, se me dificultó dedicarle el tiempo necesario a los cursos. En su momento intenté hacer la justificación por carga académica, no obstante, la oficina de becas rechazó el proceso." Estudiante \#780. "Falta 
de adaptación a la virtualidad de esos cursos" Estudiante \#1037. Todos estos aspectos se han manifestado como preocupación en el informe de la Unesco e lesalc, del año 2020:

El cambio de modalidad no está exento de una gran preocupación por parte de los líderes universitarios, puesto que ocho de cada diez están convencidos de que retener a los estudiantes para que sigan los cursos online es extremadamente problemático. Esto podría traducirse en pérdidas de estudiantes que ya no volverán a las IES cuando vuelvan a abrir sus puertas. (p. 37)

La educación no es solo el proceso de enseñanza aprendizaje, lecciones, tareas y exámenes, incluye un proceso de formación integral y de socialización que ha sido afectado por el aislamiento provocado por la pandemia y como lo indica la UNESCO "tendrán un costo" en términos "de equilibrio socioemocional que dejarán huella, en particular, en aquellos estudiantes con problemáticas preexistentes en este dominio" (Unesco e lesalc, 2020, p.16)

La mayor afectación entre la población que participó en la encuesta se evidencia directamente en la salud mental. Como consecuencia del aislamiento social, más del $90 \%$ de la población estudiantil ha sufrido de: estrés, ansiedad, sentimientos de inseguridad o incertidumbre ante la pandemia, sentimientos de frustración, de depresión, lo que afecta el desarrollo de los trabajos académicos. Aspectos que también fueron señalados por autores como (Balluerka et al., 2020 y Unesco e lesalc, 2020).

La salud mental manifiesta el estudiantado, afecta su desempeño académico: "Por estrés, ansiedad y depresión, muchas veces se me dificulta cumplir con los proyectos, trabajos o exámenes, agradecería un poco de apoyo de la persona docente para completar las asignaciones." Estudiante \#1060. “La carga emocional es principalmente la mayor afección que representa la pandemia..." Estudiante \#422.

Somos conscientes de que la experiencia de impartir lecciones de manera remota ha sido un gran reto también para la población docente, aspecto que no fue objeto de este estudio. Sin embargo, por su relación directa con la población estudiantil se debe señalar que, la población académica tampoco estaba preparada para esta transformación y, al igual que el resto de la comunidad, ha tenido que enfrentar las consecuencias del confinamiento por causa de la Pandemia COVID-19.

Según opinión de la población estudiantil encuestada, el equipo docente enfrenta dificultades para adaptar las clases a la modalidad remota, al respecto Ruiz, (2020) plantea que "los maestros universitarios" (p.110) además de tener que aprender mecanismos de la 
educación virtual en "aislamiento", han tenido que adaptarse a una manera distinta de relacionarse con la población estudiantil.

\section{Conclusiones}

El estudio demuestra que una proporción importante de la población ha desarrollado la actividad académica en un ambiente de vulnerabilidad económica y social caracterizado por el desempleo, la disminución de la jornada laboral y la reducción del ingreso familiar, como consecuencias de los efectos de la Pandemia COVID-19, como lo indica una de las personas encuestadas: "A nivel socio económico ya que ni mi familia ni yo tenemos un trabajo remunerado, se vive de siembras las cuales han sido muy afectadas con la pandemia y por ende el suplir las necesidades básicas en medio de la pandemia es muy difícil, ya que la beca no alcanza para suplir las necesidades de todos en mi hogar." (Estudiante \#226).

Esta vulnerabilidad económica y social de los hogares, genera carencias en el acceso a equipo tecnológico apropiado, a conexión a internet y acceso al software necesario para las actividades académicas y coloca a un grupo importante de población estudiantil en desventaja para continuar con el proceso educativo universitario.

Los porcentajes más altos de afectación en la población estudiantil se presentan en la salud mental, como consecuencia del confinamiento y aislamiento social, lo que amerita de respuestas urgentes por parte de autoridades universitarias y de salud a fin de evitar mayor deterioro y situaciones extremas que puedan atentar contra la vida.

A pesar de que los resultados de este estudio no se pueden generalizar para toda la población estudiantil de las carreras participantes ni de la Universidad, la información que voluntariamente aportó el estudiantado coincide con otros estudios similares, como el de Miguel (2020) y los citados en este informe.

Reiteramos, al igual que otros autores mencionados en este escrito, que es urgente realizar acciones concretas a fin de que la población estudiantil vulnerable continúe con los estudios universitarios, en especial la que ya manifestó su decisión de no continuar o de matricular parcialmente porque carece de tecnologías y conexión apropiadas para continuar estudios universitarios, y la que aún, no ha logrado desarrollar las destrezas, habilidades y autorregulación para las clases remotas.

El trabajo que inició el equipo investigador no concluyó con esta síntesis de los resultados, la información fue presentada a las autoridades de cada carrera participante, previo 
al inicio del I ciclo lectivo 2021, y aportar, como lo indicó una de las personas entrevistadas para:

Que la Universidad y la Escuela sean conscientes de la realidad que vivimos los estudiantes ante la pandemia, y como la rutina cambia estando fuera de las aulas, que sean un poco más empáticos con las situaciones familiares y personales que viven los estudiantes, que tengan en cuenta lo mucho que afecta esta situación a la salud mental y física del estudiando (Estudiante \#362)

Con el fin de que cada Unidad Académica construya alternativas para favorecer la permanencia y graduación, se entregó un archivo con el detalle de las respuestas, necesidades y solicitudes específicas de la población estudiantil participante en la investigación.

Los esfuerzos de investigación, como el expuesto, se constituyen en una herramienta muy valiosa al aportar información oportuna para la toma de decisiones de las autoridades universitarias.

Este es un primer estudio exploratorio que debe ser complementado con otros esfuerzos que den seguimiento a las consecuencias de la Pandemia COVID 19 en la permanencia estudiantil, debido a que al momento de esta publicación, la UCR continúa con las clases de manera remota y las autoridades de salud continúan utilizando, como una de las medidas de prevención, el confinamiento y el aislamiento social, con las consecuencias ya descritas en este estudio y las señaladas por Broche-Pérez et al., (2021); Balluerca et al. (2020) y Unesco e lesalc (2020).

\section{Referencias}

Aguilar, Grettel. y Pérez, Ana. (2020). Impacto de la crisis económica (COVID-19) en la población estudiantil (Trabajo presentado en la reunión El-8-2020 del Equipo de Investigación del proyecto Permanencia de la población estudiantil en la Universidad de Costa Rica). San José, Costa Rica: Autoras.

Alvarado, Carlos., Lara, Silvia. y Salas, Daniel. (16 marzo, 2020) Decreto Ejecutivo-42227Emergencia Nacional Recuperado de https://www.presidencia.go.cr/bicentenario/wpcontent/uploads/2020/03/Decreto-Ejecutivo-42227-Emergencia-Nacional.pdf

Amador, Alejandro. (2020). Acceso y uso de las TIC en los hogares costarricenses. En Programa Sociedad de la Información y el Conocimiento: Informe 2020 (Coords.), Hacia la Sociedad de la Información y el Conocimiento: Informe 2020 (pp. 223-277). Recuperado http://www.prosic.ucr.ac.cr/sites/default/files/recursos/informe prosic 2020 final 1.pdf 
Araya, Carlos. (1 de junio de 2020a). Resolución 158-2020. Universidad de Costa Rica. Recuperado de https://www.ucr.ac.cr/medios/documentos/2020/resolucion-r-1582020.pdf

Araya, Carlos. (11 de mayo de 2020b) Circular R-17-2020. Universidad de Costa Rica. Recuperado de http://www.rectoria.ucr.ac.cr/site/wp-content/uploads/2020/05/circular-r17-2020.pdf

Balluerka, Nekane., Gómez, Juana., Hidalgo, M. ${ }^{a}$ Dolores., Gorostiaga, Arantxa., Espada, José Pedro., Padilla, José Luis. y Santed, Miguel Ángel. (2020). Las consecuencias psicológicas de la COVID-19 y el confinamiento Informe de investigación. España: Universidad del País Vasco. Recuperado de https://www.ub.edu/web/ub/ca/menu eines/noticies/docs/Consecuencias psicologicas COVID-19.pdf

Banco Interamericano de Desarrollo. (2020). La Educación Superior en tiempos de COVID-19. Recuperado de https://publications.iadb.org/publications/spanish/document/Laeducacion-superior-en-tiempos-de-COVID-19-Aportes-de-la-Segunda-Reunion-delDi\%C3\%A1logo-Virtual-con-Rectores-de-Universidades-Lideres-de-America-Latina.pdf

Barrón Tirado, María Concepción. (2020). La educación en línea. Transiciones y disrupciones. En H. Casanova Cardiel (Coord.), Educación y pandemia: Una visión académica (pp.6674). Ciudad de México: UNAM. Recuperado de http://132.248.192.241:8080/ispui/bitstream/IISUE UNAM/540/1/BarronC 2020 La ed ucacion en linea.pdf

Broche-Pérez, Yunier, Fernández-Castillo, Evelyn y Reyes, Darly Alejandra. (2021) Consecuencias psicológicas de la cuarentena y el aislamiento social durante la pandemia de COVID-19. Revista Cubana de Salud Pública, 46(Suppl 1). Recuperado de https://scielosp.org/article/rcsp/2020.v46suppl1/e2488/es/

Camacho, Alessandra. (2020). Educación remota en tiempos de pandemia del covid-19: nuevas experiencias y desafíos. Online Braz J Nurs. 19(4). Recuperado de https://docs.bvsalud.org/biblioref/2021/03/1145525/6475-es.pdf

Comisión Económica para América Latina (CEPAL) y Organización de las Naciones Unidas para la Educación, la Ciencia y la Cultura (UNESCO). (2020). Informe COVID-19. La Educación en tiempos de la pandemia de COVID-19. Recuperado de https://repositorio.cepal.org/bitstream/handle/11362/45904/1/S2000510 es.pdf

Del Valle, Damián. (2008). La Universidad como derecho en el marco de las tendencias de la educación superior en la región. En Claudio Suasnábar y Damián Del Valle (Coords.) Política y tendencias de la educación superior en la región a 10 años de la CRES 2008 (pp. 37-54). Recuperado de http://biblioteca.clacso.edu.ar/clacso/se/20180530031649/Poltica y tendencia.pdf

Delgado, Carmen. (2014). Viajando a Ítaca por mares cuantitativos: Manual de ruta para investigación en grado y postgrado. España: Amarú. 
Espinosa-Castro, Jhon-Franklin., Hernández-Lalinde, Juan., y Mariño Castro, Laydi. (2020). Estrategias de permanencia universitaria. AVFT-Archivos Venezolanos de Farmacología y Terapéutica, 39(1), 88-97. Doi https://doi.org/10.5281/zenodo.4065045

Ezcurra, Ana. (2011). Igualdad en Educación Superior: Un desafío Mundial. Buenos Aires, Argentina: Editorial UNGS.

García, Ivet. y Bustos, Ruth Belinda. (2021). La autorregulación del aprendizaje en tiempos de pandemia: una alternativa viable en el marco de los procesos educativos actuales. Diálogos sobre Educación, 12(22). Recuperado de file://C:/Users/Owner/Downloads/914-Texto\%20del\%20art\%C3\%ADculo-4581-1-1020201230.pdf

Gutiérrez, Ilse. y Kikut, Lorena. (2020). Índice de condición socioeconómica de la población estudiantil universitaria estatal: Metodología y resultados. San José, C. R.: CONAREOPES. Recuperado de http://repositorio.conare.ac.cr/handle/20.500.12337/8040

Kikut, Lorena. (2020). Análisis de resultados de la evaluación de la virtualización de cursos en la UCR ante la pandemia por COVID-19: Perspectiva estudiantil. Recuperado de https://cutt.ly/gQBizZo

López, Mónica., y Rodríguez, Santiago Andrés. (2020). Trayectorias escolares en la educación superior ante la pandemia ¿continuar, interrumpir o desistir? En Instituto de Investigaciones sobre la Universidad y la Educación (Ed.), Educación y pandemia. Una visión académica (pp. 103-108). México, UNAM. Recuperado de http://www.iisue.unam.iisue/covid/educacion-y-pandemia

Miguel, José Antonio. (2020). La educación superior en tiempos de pandemia: una visión desde dentro del proceso formativo. Revista Latinoamericana de Estudios Educativos, 50(Número especial). Recuperado de https://www.redalyc.org/jatsRepo/270/27063237017/html/index.html

Naciones Unidades. (21 octubre, 2015). Resolución aprobada por la Asamblea General el 25 de septiembre de 2015. Transformar nuestro mundo: la Agenda 2030 para el Desarrollo Sostenible Recuperado de https://undocs.org/es/A/RES/70/1

Navea, Ana. (2018). El aprendizaje autorregulado en estudiantes de ciencias de la salud: recomendaciones de mejora de la práctica educativa. Educación Médica, 19(4). Recuperado de https://www.elsevier.es/es-revista-educacion-medica-71-pdf$\underline{\mathrm{S} 157518131730013 \mathrm{X}}$

Neira, Juan. (2020). Factores y Variables asociadas al rezago en estudiantes de la Universidad de la Costa (Tesis de Maestría). Universidad de la Costa CUC, Colombia. Recuperado de https://hdl.handle.net/11323/6348

Ordaz, Adriana y García, Octaviano. (2018). El estudio del rendimiento académico en nivel universitario. Aproximaciones al estado del conocimiento. Congresos CLABES, s.v.(4), 304-313. Recuperado de https://revistas.utp.ac.pa/index.php/clabes/article/view/1962/2900 
Organización de las Naciones Unidas para la Educación, la Ciencia y la Cultura (Unesco). (2015). Declaración del Incheon. Educación 2030: Hacia una educación inclusiva y equitativa de calidad y un aprendizaje a lo lardo de toda la vida. Recuperado de http://www.Unesco.org/new/fileadmin/MULTIMEDIA/FIELD/Lima/pdf/INCHE 2.pdf

Organización de las Naciones Unidas para la Educación, la Ciencia y la Cultura (Unesco) e Instituto Internacional para la Educación Superior en América Latina y el Caribe (lesalc). (2020). COVID-19 y educación superior: De los efectos inmediatos al día después. Recuperado de http://www.lesalc.Unesco.org/wp-content/uploads/2020/05/COVID-19ES-130520.pdf

Regueyra, María Gabriela. (2010). El sistema de Becas por condición socioeconómica y la accesibilidad la Educación universitaria: una mirad desde los indicadores de gestión 2002008. Actualidades Investigativas en educación, 10(Número especial). Recuperado de https://revistas.ucr.ac.cr/index.php/aie/article/view/10162/18019

Rovelli, Laura Inés. (2008). Las Conferencias mundiales y regionales de Educación Superior como instrumento de política. Mediaciones y reformulaciones latinoamericanas de fines del siglo XX y principios del XXI. En Claudio Suasnábar y Damián Del Valle (Coords.), Política y tendencias de la educación superior en la región a 10 años de la CRES 2008 (pp. 57-71). Recuperado de http://biblioteca.clacso.edu.ar/clacso/se/20180530031649/Poltica y tendencia.pdf

Ruiz, Estela. (2020). La práctica docente universitaria en ambientes de educación a distancia. Tensiones y experiencias de cambio. En Instituto de Investigaciones sobre la Universidad y la Educación (Ed.), Educación y pandemia. Una visión académica (pp. 109-113). México: UNAM. Recuperado de http://132.248.192.241:8080/xmlui/bitstream/handle/IISUE UNAM/545/RuizLarraguivel E 2020 La practica docente.pdf?sequence=1\&isAllowed $=y$

Salama, Pierre. (2021). Contagio viral, contagio económico. Riesgos políticos en América Latina. Recuperado de https://www.clacso.org.ar/librerialatinoamericana/libro detalle.php?orden=\&id libro=2313\&pageNum rs libros=0\&totalR ows rs libros $=1478$

Solórzano, María Julieta., Regueyra, María Gabriela., Esquivel, Catalina. y Arias, Freddy. (2020). Permanencia de la población estudiantil a partir de un estudio longitudinal. Educación Superior y Sociedad, 32(2). Recuperado de https://www.lesalc.Unesco.org/ess/index.php/ess3

Torrano, Fermín., Fuentes, Juan Luis. y Soria, María. (2017). Aprendizaje autorregulado: estado de la cuestión y retos psicopedagógicos. Perfiles Educativos, 39(156). Recuperado de http://www.scielo.org.mx/pdf/peredu/v39n156/0185-2698-peredu-39156-00160.pdf

Universidad de Costa Rica, Vicerrectoría de Investigación. (2015). Resolución VI-1894-2015. Recuperado de https://vinv.ucr.ac.cr/sites/default/files/files/RESOLUCION\%20VI-18942015.pdf 
Universidad de Costa Rica, Vicerrectoría de Investigación. (2015). Resolución VI-2734-2015. Recuperado de https://vinv.ucr.ac.cr/sites/default/files/files/RESOLUCI\%C3\%93N\%20VI-2734-2015.pdf

Universidad de Costa Rica. (11 de marzo de 2020a). Comunicado 3: La UCR solicita a sus docentes implementar clases bajo una modalidad virtual. Recuperado de https://www.ucr.ac.cr/medios/documentos/2020/comunicado-3.pdf

Universidad de Costa Rica. (11 de marzo de 2020b). Comunicado 5: Uso de plataforma de Mediación Virtual de la UCR. Recuperado de https://www.ucr.ac.cr/medios/documentos/2020/comunicado-5-.pdf

Universidad de Costa Rica. (11 de marzo de 2020c). Comunicado 6: la UCR fortalece plataformas tecnológicas para virtualizar sus actividades. Recuperado de https://www.ucr.ac.cr/medios/documentos/2020/comunicado-6 1.pdf

Universidad de Costa Rica. (2005). Estatuto Orgánico. Recuperado de https://www.cu.ucr.ac.cr/normativ/estatuto organico.pdf

Universidad de Costa Rica. (2015). Reglamento de adjudicación de becas a la población estudiantil. Recuperado https://www.cu.ucr.ac.cr/normativ/adjudicacion de becas 2015.pdf

Universidad de Costa Rica. (2020). Así es como la UCR afronta el nuevo coronavirus. Recuperado de https://www.ucr.ac.cr/coronavirus.html

Universidad de Costa Rica. (2021). Estadísticas de la Oficina de Becas I ciclo 2020 (Documento Interno). San José, Costa Rica. UCR.

Unzué, Martín. (2008). ¿Podemos hablar de una Universidad Latinoamericana? Exclaustración y compromiso como legado. En Claudio Suasnábar y Damián Del Valle (Coords.) Política y tendencias de la educación superior en la región a 10 años de la CRES 2008 (pp. 7388).

Recuperado

de http://biblioteca.clacso.edu.ar/clacso/se/20180530031649/Poltica y tendencia.pdf

Vives-Varela, Tania., Durán-Cárdenas, Cassandra., Varela-Ruíz, Margarita. y Fortoul van der Goes, Teresa. (2014). La autorregulación en el aprendizaje, la luz de un faro en el mar. Investigación en Educación Médica, 3(9). Recuperado de: http://www.scielo.org.mx/pdf/iem/v3n9/v3n9a6.pdf

Zambrano-Matamala, Carolina., Díaz-Mujica, Alejandro., Pérez-Villalobos, María V. y Rojas Díaz, Darío. (2020). Análisis de estrategias de autorregulación en estudiantes de pedagogía de una universidad chilena. En Formación Universitaria, 13(5) Recuperado de https://scielo.conicyt.cl/pdf/formuniv/v13n5/0718-5006-formuniv-13-05-223.pdf 
Revista indizada en

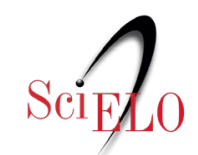
redalyc sy latindex

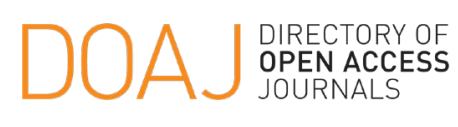

Distribuida en las bases de datos:

- Dialnet
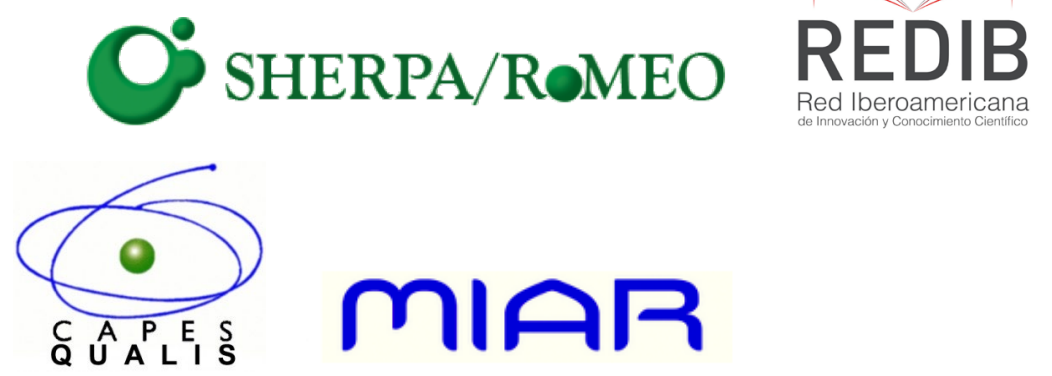

MIAR 